\title{
Journal of Solid State Lighting
}

Robert F Karlicek $\mathrm{Jr}^{1 *}$, Ruiqing Ma ${ }^{2 \dagger}$, Ching-Cherng Sun ${ }^{3+}$ and Georges Zissis ${ }^{4+}$

* Correspondence: karlir@rpi.edu

${ }^{\dagger}$ Equal contributors

${ }^{1}$ Rensselaer Polytechnic Institute, Troy, NY, USA

Full list of author information is

available at the end of the article
The development of highly efficient Solid State Lighting (SSL) technology has evolved rapidly over the past two decades by drawing on a wide range of fundamental and applied research across multiple scientific disciplines. Even as SSL lighting systems are penetrating conventional lighting markets at commercially significant levels, rapid evolution of the core technological foundations of SSL continues. Moreover, the broad range of new SSL capabilities enabled by the electronic generation of efficient, tunable light is redefining how illumination is packaged, controlled and integrated with emerging networked intelligent services and systems. These extensive, new SSL capabilities are also driving the development of novel illumination system applications in healthcare, horticulture and communications.

Today, the range of research topics critical to the continued development and application of SSL technologies for the benefit of society is one of the most interdisciplinary of any modern field of research. The publication of scholarly work on SSL technology and applications has largely been partitioned to venues catering to classical divisions of the physical sciences and engineering disciplines with little overlap in the fields of illumination engineering and human factors research. While the past decade has seen the explosion of new, more interdisciplinary repositories of scholarly research, none have been devoted solely to the wide range of disciplines comprising this broad, new field of SSL development and deployment. The Journal of Solid State Lighting is being launched to provide such a venue, as the editors, along with the publisher, Springer, felt that a venue serving the holistic development of advanced illumination materials, devices, systems and application research would be a benefit to the SSL research community and help accelerate progress in this critical field.

The Journal of Solid State Lighting will accept submissions of original, scholarly work on all topics that impact the development of LED- and OLED-based SSL ranging from the efficient generation and control of SSL-based illumination to the design of new applications uniquely enabled by SSL systems including illumination engineering, the interaction of light with living systems and the integration of SSL with other increasingly internet enabled systems and services. Ideally, journal submissions will expand the growth of interdisciplinary SSL research by connecting basic and applied semiconductor and materials research with transformative research on the packaging, control and societal impact of new SSL system features and applications. Springer and the Editorial Board look forward to working with scientists, engineers, physicians and designers to develop the Journal of Solid State Lighting as the primary venue for publication of scholarly work related to core SSL technology and its uses.

(c) 2014 Karlicek et al.; licensee Springer. This is an Open Access article distributed under the terms of the Creative Commons Attribution License (http://creativecommons.org/licenses/by/4.0), which permits unrestricted use, distribution, and reproduction in any medium, provided the original work is properly credited. 
Author details

${ }^{1}$ Rensselaer Polytechnic Institute, Troy, NY, USA. ${ }^{2}$ Universal Display Corporation, Trenton, NJ, USA. ${ }^{3}$ National Central University, Zhongli, Taiwan. ${ }^{4}$ Toulouse University, Toulouse, France.

Received: 19 March 2014 Accepted: 20 March 2014

Published: 23 April 2014

doi:10.1186/2196-1107-1-1

Cite this article as: Karlicek et al.: Journal of Solid State Lighting. Journal of Solid State Lighting 2014 1:1.

Submit your manuscript to a SpringerOpen ${ }^{\odot}$ journal and benefit from:

- Convenient online submission

- Rigorous peer review

- Immediate publication on acceptance

- Open access: articles freely available online

- High visibility within the field

- Retaining the copyright to your article

Submit your next manuscript at $>$ springeropen.com 